\title{
Retroperitoneoscopic adrenalectomy 20 years, and more, after. A review
}

\begin{abstract}
Adrenalectomy has been a challenging surgery mainly due to the deep position of the adrenal gland in the retro-peritoneum under the diaphragm. Laparoscopy and the laparoscopic retroperitoneal approach offered a newer, easier, faster way to remove adrenals. The development of these techniques are described, up to nowadays, at what time a wide choice of tailored approaches to remove adrenal gland, according to its size, disease's status and position, are available.
\end{abstract}

Keywords: retroperitoneoscopy, laparoscopy, adrenalectomy, adrenal tumours
Volume 3 Issue 5 - 2016

\author{
Alberto Mandressi, Gianluigi Taverna \\ Humanitas Mater Domini, Italy
}

Correspondence: Alberto Mandressi, Humanitas Mater Domini,Via Gerenzano 2, 21053 - Castellanza (VA), Italy, Tel 39 033। 476 22I, Email alberto.mandressi@auro.it

Received: July 27, 2016 | Published: October 18,2016

\section{Introduction}

Adrenalectomy has been covered by a long history of techniques: the anatomical location of the adrenal glands in the retro-peritoneum, their scattered arterial vascularization, the stumpy right venous drainage, the different pathologies that indicate their removal, the different sizes of the glands to be removed, the infrequent but not rare occurrence of large tumors, the often bilateral hypertrophic and hyper-functioning glands have impelled the surgeons to approach adrenalectomy with many surgical techniques. Until the end of the eighties of the twentieth century the large open transperitoneal access was the most applied surgical strategy. In some cases for small bilateral hyper-functioning gland a bilateral open posterior approach was performed. ${ }^{1}$ Nowadays instead, both the laparoscopic and retroperitoneoscopic approaches are the standard procedures to remove adrenal glands. ${ }^{2}$ What happened in the early years of the century was the clinical development of laparoscopy mainly for biliary diseases. ${ }^{3}$ Afterwards urologists were interested in the laparoscopic technique and in 1992 Clayman first published a laparoscopic nephrectomy method.

However, kidney and adrenal glands are retroperitoneal organs and the standard urologist's approach to the kidney was preferably retroperitoneal. For these reasons the idea for approaching minimally invasively the retroperitoneal organs via retroperitoneum was immediately considered. ${ }^{5}$ On the other hand the enthusiasm was disappointed by the early attempts to approach the kidney and the adrenals for the peritoneum has no space to be dilated. ${ }^{6,7}$ In 1993 two different methods to create a space in the retroperitoneum were proposed in two different countries. Gaur in India ${ }^{8}$ with the patient in flank position, made a hole in the skin of the posterior lumbar space through which introduced a catheter with a glow finger secured on the tip. By inflating the finger tip like a balloon a space into the retroperitoneal fat was developed, enough to introduce trocars and carry on a retroperitoneoscopic procedure.

In contrast, in Italy Mandressi et al. ${ }^{9}$ applied a well known method used by radiologist, before the availability of contrast liquid, to enhance the kidney profile with $\mathrm{x}$-rays by insufflating $\mathrm{CO}_{2}$ through a needle percutaneous insertion in the retroperitoneum. The patient, previously supplied with an ureteral catheter on the operative side, was put in prone position; under fluoroscopy a Verres needle was inserted between the ureter, with the catheter, and the kidney lower pole: by slightly shifting medially the ureter the correct position was checked and the $\mathrm{CO}_{2}$ insufflation started. By fluoroscopy the progression of the inflation was controlled: when a bright area wide enough to lift the pole of the kidney has been created, the first trocar could be inserted in the area, having made a vertical incision of about $1 \mathrm{~cm}$ just on the angle between the XII rib and the sacrospinalis muscle. Then inserting the optic in the first trocar, all the others ports were made, comparing the inner view with the fluoroscopic image to check the correct position.

Both methods described above scouted the retroperitoneal approach. They were successively improved with experience melting together both the experiences: a finger dissection was used to create the initial space instead of a balloon ${ }^{10}$ and the fluoroscopy was abandoned also by ourselves. ${ }^{11-24}$ By the end of the 20th century the laparoscopic and retroperitoneoscopy adrenalectomy had gained the benchmark for the adrenal surgery: "After the comparative experience of multicentric studies $^{25,26}$ it is assessed that laparoscopic adrenalectomy is feasible and safe with a low ratio of cost/benefit regardless the pathology. Only large tumor $(>6 \mathrm{~cm})$ are still under investigation ${ }^{27}$ " The words are quoted from EAU Laparoscopic Guidelines. ${ }^{28}$

The statements of EAU guidelines were the results of many scattered experiences in performing laparoscopic adrenalectomies with different techniques: laparoscopic adrenalectomies are characterized not only by the access route to retroperitoneum (laparoscopic or retroperitoneoscopic), but also by the patient's position on the operatory table (prone, flank) and by the number, size and position of the trocars. In fact, adrenalectomy has been from the beginning a challenging surgery: in the Guillonneau's classification ${ }^{29}$ laparoscopic adrenalectomy scored the highest difficulty. Obviously the difficulty rank depends on many factors: pathology that affects the gland, size and shape of the gland, position (right or left are different), frame of the patient i.e. the amount of fat surrounding the gland and the deepness of the gland with respect to the skin, and not least, the experience of the surgeon.

The fat had slowed down the initial series of retroperitoneoscopic procedures, mainly when hyperfunctioning small glands poured 
a large amount of corticosteroids in the blood stream. Entering the retroperitoneum into a large amount of fat was like operating in a tick yellowish fog. An ultrasonic device was developed to suck the fat thus letting the retroperitoneal structures appear. ${ }^{30}$ As the experience of the surgeons went on, the anatomy of the retroperitoneum went clearly standardized. The identification of the psoas muscle, the diaphragmatic pillar and the peritoneum let's take clearly the cardinal points from where start the dissection. ${ }^{11}$ It should be kept in mind that adrenals in general, moreover cortical adenomas, are fragile; therefore the gland shouldn't be touched by the instruments; instead it is the fat that surrounds the gland that must be lifted, shifted and moved to dissect the gland from the surrounding structures. ${ }^{24}$

The prone position was heralded as benchmark of laparoscopic adrenalectomy in a series of primary aldosteronism: ${ }^{31}$ it is obvious that the size of the gland in this pathology allows a direct posterior approach. The space that can be create with the patient in prone position enable the surgeon to safely dissect a gland up to around $5 \mathrm{~cm}$ in diameter. ${ }^{22,32-34}$ Tumors larger than $6 \mathrm{~cm}$ are better and more safely excised with the patient in flank position either via retroperitoneal approach or via anterior laparoscopic approach. However the above mentioned general statement can be updated with the experience achieved by large series of procedures. ${ }^{35}$ Other issues when comparing the 3 techniques of laproscopic adrenalectomy (retroperitoneoscopic in prone position, trans and retroperitoneal approach in flank position) are: the space of the working room, the number of trocars needed, and the organs involved in the procedure and the working time. ${ }^{36-40}$ The retroperitoneoscopy in prone position scores the best result in terms of operative time, intraoperatory complications, number and sizes of the trocars, any involvement of peritoneal organs. However the working room of the transperitoneal laparoscopic approach is without any doubt the largest, but needs more ports. Does the adrenal pathology affect the way to approach the adrenals? The answer is conclusively no, provided that a properly preoperative staging has been performed: in fact when dealing with pheochromocytomas, the presence of coexisting paragangliomas should be ruled out: when present it should be dissected together with the adrenal pheochromocytoma. When multiple lesions are present a partial adrenalectomy can be performed. ${ }^{41,42}$

\section{Conclusion}

After twenty years and more, retroperitoneoscopic adrenalectomy in prone position still plays the first choice when adrenalectomy should be accomplished. With 3 ports ( 2 of $10 \mathrm{~mm}$ and 1 of $5 \mathrm{~mm}$ ), a mean operative time 60 minutes without blood losses and major complications it gets the best scores in most of the cases. According to the experience of surgeon, size of the tumor, frame and health status of the patient, pathology of the gland, the laparoscopy or the retroperitoneoscopy in flank position can be as well performed. Open surgery is nowadays seldom necessary for very huge masses, sometimes up to $25 \mathrm{~cm}$ in diameter, having venous drainage the size of a renal vein.

\section{Acknowledgments}

None.

\section{Conflicts of interest}

The author declares there is no conflict of interest.

\section{References}

1. Libertino JA, Novick JE. Adrenal Surgery. Urol Clin North Am. 1989;16:417-606.

2. Stefanidis D, Goldfarb M, Kercher WK, et al. Guidelines for the Minimally Invasive Treatment of Adrenal Pathology, SAGES. 2013.

3. Cuschieri A, Berci G. Laparoscopic biliary surgery, Oxford: Blackwell Scientific Publications. 1990.

4. Clayman RV, Kavoussi LR, Soper NJ, et al. Laparoscopic nephrectomy: review of the initial ten cases. J Endourol. 1992;6(2):127-132.

5. Hubert JC, Fraley EE. Laparoscopic retroperitoneal lymphadenectomy: new approach to pathologic staging of clinical stage I germ cell tumors of the testis. J Enourol. 1992;6(2):123-125.

6. Winfield HN, Donovan JF, See WA, et al. Urological laparoscopic surgery. J Urol. 1991;146(4):941-948.

7. Coptcoat MJ, Wickham JEA. Laparoscopy in Urology. Min Invas Ther. 1992;1:337-342.

8. Gaur DD, Agarwal DL, Purohit KC. Retroperitoneal laparoscopic nephrectomy: initial case report. J Urol. 1993;149(1):103-105.

9. Mandressi A, Buizza C, Antonelli D, et al. Retro-extraperitoneal laparoscopic approach to excise retroperitoneal organs: kidny and adrenal gland. Min Invas Ther. 1993;2:213-220.

10. Gasman D, Saint F, Barthelemy Y, et al. Retroperitoneoscopy: a laparoscopic approach for adrenal and renal surgery. Urology. 1996;47(6):801-806.

11. Mandressi A, Buizza C, Antonelli D, et al. Retroperitoneoscopy. Ann Urol. 1995;29(2):91-96.

12. Mandressi A, Buizza C, Zaroli A. Laparoscopic nephrectomies and adrenalectomies by posterior extraperitoneal approach. $J$ Endourology. 1993;7(Suppl 1):S175

13. Mandressi A, Buizza C, Belloni M. Retro extraperitoneal laparoscopic nephrectomy (REPLNx). J Endourology. 1993; 7(Suppl 1):S232.

14. Mandressi A, Buizza C, Belloni M. Posterior extraperitoneal laparoscopic adrenalectomy for pheochromocitoma. J Endourology. 1993;7(Suppl 1):S233.

15. Vargas HI, Kavoussi LR. Laparoscopic adrenalectomy: a new standard of care. Urology. 1997;49:673-678.

16. Mandressi A, Buizza C, Belloni M. Posterior extraperitoneal laparoscopic adrenalectomy for pheochromocitoma. Min Invas Ther. 1993;2(Supp 1):85.

17. Mandressi A, Buizza C, Belloni M. Laparoscopic nephrectomies and adrenalectomies by posterior extraperitoneal approach. Min Invas Ther. 1993;2(Supp 1):54.

18. Mandressi A, Buizza C, Zaroli A. Retroperitoneal urological laparoscopic surgery" $23^{\circ}$ Congress. International Society of Urology, Sydney, Australia, 1994. p. 285.

19. Mandressi A, Buizza C, Antonelli D. Retroperitoneal laparoscopic adrenalectomy. Min Invas Ther. 1995;4 (Supp 1):18.

20. Mandressi A, Buizza C, Antonelli D. Laparoscopic retroperitoneal nephrectomy and adrenalectomy: clinical analysis of 23 cases. $J$ Endourology. 1995;9(Suppl 1):S100

21. Mandressi A, Buizza C, Antonelli D. Retroperitoneoscopic nephrectomy and adrenalectomy: our experience. Min Invas Ther. 1996;5(Supp 1):77. 
22. Mandressi A, Buizza C, Antonelli D. Four years experience with retroperitoneoscopic adrenalectomy. $J$ Endourology. 1996;10(Suppl 1):S135.

23. Mandressi A. Adrenalectomy in Extraperitoneal Laparoscopic Surgery. In: Eden CG editor, Oxford, Blackwell Science. 1997. p 119-130.

24. Mandressi A. Retroperitoneal Laparoscopic Adrenalectomy in Retroperitoneal Laparoscopic Urology. In: Gaur DD editor, New Delhi, Oxford University Press. 1997. p. 211-227.

25. Mancini F, Mutter D, Peix JL, et al. Experiences with adrenalectomy in 1997. Apropos of 247 cases. A multicenter prospective study of the French-speaking Association of Endocrine Surgery. Chirurgie. 1995;124(4):368-374.

26. Terachi T, Yoshida O, Matsuda T, et al. Complications of laparoscopic and retroperitoneoscopic adrenalectomies in 370 cases in Japan: a multiinstitutional study. Biomed Pharmacother. 2000;54(Suppl 1):211-214.

27. Hobart MG, Gill IS, Schweizer D, et al. Laparoscopic adrenalectomy for large-volume ( $>$ or $=5 \mathrm{~cm}$ ) adrenal masses. J Endourol. 2000;14(2):149_ 154.

28. Doublet JD, Janetschek G, Joyce A. EAU Laparoscopy guidelines, Arnhem. 2001.

29. Guillonneau B, Abbou CC, Doublet JD, et al. Proposal for a "European Scoring System for Laparoscopic Operations in Urology". Eur Urol. 2001;40(1):2-6.

30. Suzuki K, Fujita K, Ushiyama T, et al. Efficacy of an ultrasonic surgical system for laparoscopic adrenalec-tomy. J Urol. 1995;154(2 Pt 1):484 487.

31. Nash PA, Leibovitch I, Donohue JP. Adrenalectomy Via the Dorsal Approach: A Benchmark for Laparoscopic Adrenalectomy. J Urol. 1995;154(5):1652-1654.

32. Tsuru N, Suzuki K, Ushiyama T, et al. Laparoscopic Adrenalectomy for Large Adrenal Tumors. J Endourol. 2005;19(5):537-540.
33. Hobart MG, Gill IS, Schweizer D, et al. Laparoscopic adrenalectomy for large-volume ( $>$ or $=5 \mathrm{~cm}$ ) adrenal masses. J Endourol. 2000;14(2):149154.

34. Suzuki K, Kageyama S, Hirano Y, et al. Comparison of 3 Surgical Approaches to Laparoscopic Adrenalectomy: A Nonrandomized, Background Matched Analysis. J Urol. 2001;166(2):437-443.

35. Walz MK, Peitgen K, Walz MV, et al. Posterior retroperitoneoscopic adrenalectomy: lessons learned within five years. World J Surg. 2001;25(6):728-734.

36. Takeda M, Go H, Watanabe R, et al. Retroperitoneal laparoscopic adrenalectomy for functional adrenal tumors: comparison with conventional transperitoneal laparoscopic adrenalectomy. J Urol. 1997;157:19-23.

37. Terachi T, Yoshida O, Matsuda T, et al. Complications of laparoscopic and retroperitoneoscopic adrenalectomies in 370 cases in Japan: a multiinstitutional study. Biomed Pharmacother. 2001;54 (Suppl 1):211-214.

38. Lezoche E, Guerrieri M, Feliciotti F, et al. Anterior, lateral, and posterior retroperitoneal approaches in endoscopic adrenalectomy. Surg Endosc. 2002;16(1):96-99.

39. Naya Y, Nagata M, Ichikawa T, et al. Laparoscopic adrenalectomy: comparison of transperitoneal and retroperitoneal approaches. BJU Int. 2002;90(3):199-204.

40. Lezoche E, Guerrieri M, Crosta F, et al. Flank approach versus anterior sub-mesocolic access in left laparoscopic adrenalectomy: a prospective randomized study. Surg Endosc. 2002;22(11):2373-2378.

41. Janetschek G, Finkenstedt G, Gasser R, et al. Laparoscopic Surgery For Pheochromocytoma: Adrenalectomy, Partial Resection, Excision Of Paragangliomas. J Urol. 1998;160(2):330-334.

42. Tanaka M, Tokuda N, Koga H, et al. Laparoscopic adrenalectomy for pheochromocytoma: comparison with open adrenalectomy and comparison of laparoscopic surgery for pheochromocytoma versus other adrenal tumours. J Endourol. 2000;4(5):427-431. 